\title{
Evaluation of purity with its uncertainty value in high purity lead stick by conventional and electro-gravimetric methods
}

\author{
Nahar Singh*, Niranjan Singh, S Swarupa Tripathy, Daya Soni, Khem Singh and Prabhat K Gupta
}

\begin{abstract}
Background: A conventional gravimetry and electro-gravimetry study has been carried out for the precise and accurate purity determination of lead $(\mathrm{Pb})$ in high purity lead stick and for preparation of reference standard. Reference materials are standards containing a known amount of an analyte and provide a reference value to determine unknown concentrations or to calibrate analytical instruments. A stock solution of approximate $2 \mathrm{~kg}$ has been prepared after dissolving approximate $2 \mathrm{~g}$ of $\mathrm{Pb}$ stick in $5 \%$ ultra pure nitric acid. From the stock solution five replicates of approximate $50 \mathrm{~g}$ have been taken for determination of purity by each method. The Pb has been determined as $\mathrm{PbSO}_{4}$ by conventional gravimetry, as $\mathrm{PbO}_{2}$ by electro gravimetry. The percentage purity of the metallic $\mathrm{Pb}$ was calculated accordingly from $\mathrm{PbSO}_{4}$ and $\mathrm{PbO}_{2}$

Results: On the basis of experimental observations it has been concluded that by conventional gravimetry and electro-gravimetry the purity of $\mathrm{Pb}$ was found to be $99.98 \pm 0.24$ and $99.97 \pm 0.27 \mathrm{~g} / 100 \mathrm{~g}$ and on the basis of $\mathrm{Pb}$ purity the concentration of reference standard solutions were found to be $1000.88 \pm 2.44$ and $1000.81 \pm 2.68 \mathrm{mg} \mathrm{kg}^{-1}$ respectively with $95 \%$ confidence level $(k=2)$. The uncertainty evaluation has also been carried out in $\mathrm{Pb}$ determination following EURACHEM/GUM guidelines. The final analytical results quantifying uncertainty fulfills this requirement and gives a measure of the confidence level of the concerned laboratory.

Conclusions: Gravimetry is the most reliable technique in comparison to titremetry and instrumental method and the results of gravimetry are directly traceable to SI unit. Gravimetric analysis, if methods are followed carefully, provides for exceedingly precise analysis. In classical gravimetry the major uncertainties are due to repeatability but in electro-gravimetry several other factors also affect the final results.
\end{abstract}

Keywords: Lead, Conventional gravimetric, Electro gravimetric, Buoyancy, Uncertainty evaluation

\section{Background}

There is an increasing interest in $\mathrm{Pb}$ in the various matrixes because of its harmful effects on human beings. The $\mathrm{Pb}$ transfer through various processes from rocks, sediments, ground water, sludge etc. and causes negative effect on human beings. Lead as a metal has been widely used in industry for many years. Lead is omnipresent in the environment, either from natural resources or from pollutants. WHO/Codex alimentarius has established $0.01 \mathrm{mg} \mathrm{L}^{-1}$ maximum permissible limits of $\mathrm{Pb}$ in drinking water and 0.02 to $0.3 \mathrm{mg} \mathrm{L}^{-1}$ in food items [1]. Exposure to high

\footnotetext{
* Correspondence: naharsingh@mail.nplindia.org

Analytical Chemistry Division, CSIR- National Physical Laboratory,

Dr K. S. Krishnan Marg, New Delhi 110012, India
}

concentrations of $\mathrm{Pb}$ can cause serious health problems, including nervous system dysfunction of fetuses and infants, hemotoxic effects, reproductive dysfunction, gastrointestinal tract alterations, nephropathies, Alzheimer's disease, anemia etc. [2]. Thus accurate and precise determination of $\mathrm{Pb}$ is of prime importance because it is directly related to human health. To determine $\mathrm{Pb}$ at $\mathrm{ppm}$ or sub-ppm levels, some analytical instruments with highsensitivity detection capabilities are available, including inductively coupled plasma mass spectroscopy (ICP-MS) and graphite furnace atomic absorption spectroscopy (GFAAS) [3-8]. Ion chromatography has also been used for lead determination; however, its sensitivity is not as good as that of ICP-MS and GFAAS [9,10]. ASTM E161304 is the Standard Test Method for determination of lead
() ChemistryCentral

(c) 2013 Singh et al.; licensee Chemistry Central Ltd. This is an Open Access article distributed under the terms of the Creative Commons Attribution License (http://creativecommons.org/licenses/by/2.0), which permits unrestricted use, distribution, and reproduction in any medium, provided the original work is properly cited. 
by ICP-AES, Flame Atomic FAAS, or GFAAS Techniques. These techniques are very sensitive and can be used only for trace analysis and always required reference standard to calibrate the instrument. The higher concentration can not be determined by these techniques due to several dilution factors. Usually the higher concentration of lead can be determined by titremetry using sodium thiosulphate, EDTA, ammonium molybdate as titrant, or electro gravimetry as $\mathrm{PbO}_{2}$ [11] or conventional gravimetry as lead chromate, lead molybdate, lead sulphate, and lead subacetate [12]. Out of these techniques conventional gravimetry method is the primary method of measurement and most reliable technique in comparison to titremetry and instrumental method and results of gravimetry are directly traceable to SI unit.

In chemical metrology the reliability of the results in international trade is required for the acceptance of the analytical result by the users within the country or outside the country. This can be achieved by providing traceability of data characterizing products or for quality control/assurance of methodology used to analyze products. Quantifying uncertainty of analytical results fulfills this requirement and gives a measure of the confidence level of the analytical result. The estimation of uncertainty in the measurements has been given in ISO/EURACHEM guidelines [13-15]. The measurement uncertainty is carried out by quantifying of uncertainty in measurement of various steps and further by combination of potential sources of uncertainty of the entire experiment. The uncertainty has been classified as 'Type A', which is determined by statistical analysis of several observations. Second is or 'Type B' method which is determined by other ways than statistical analysis of a series of results.

Keeping in view the above facts, an attempt has been made by analyzing $\mathrm{Pb}$ by using two different gravimetry approaches; conventional gravimetry and electro-gravimetry. In the proposed process we have determined the purity of the $\mathrm{Pb}$ content with uncertainty value in the high purity lead stick procured from Sigma Aldrich. The uncertainty value determined is depends on different sources viz. uncertainty due to precision, repeatability, weighing, atomic mass of $\mathrm{Pb}$ and air buoyancy. In literature number of studies has been published on the

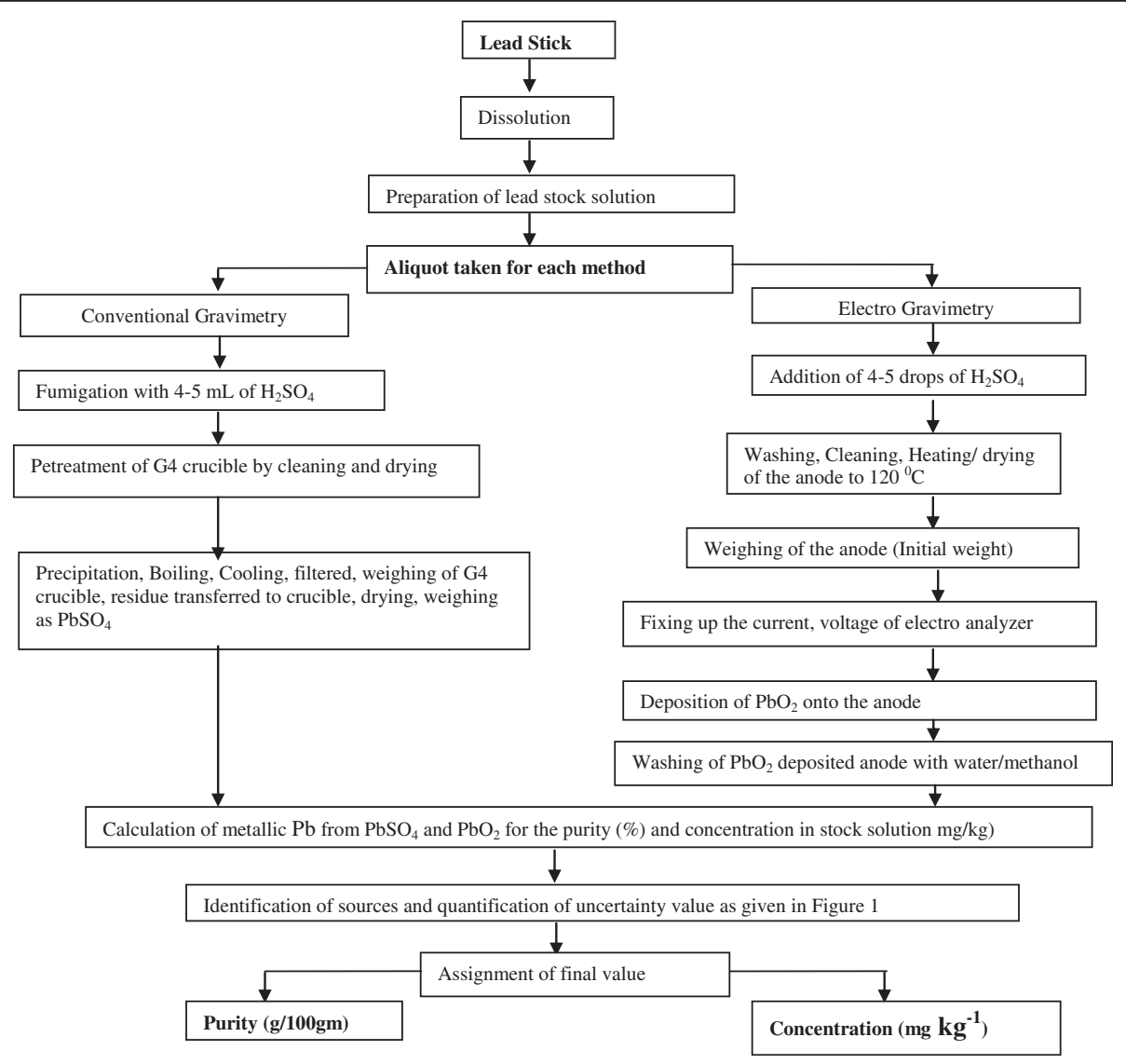

Figure 1 Flow chart for the purity analysis of lead by conventional and electro gravimetric method. 
Table 1 Various evaluated components for the determination of Lead

\begin{tabular}{|c|c|c|c|c|c|c|c|}
\hline $\begin{array}{l}\text { Sample } \\
\text { I.D. }\end{array}$ & $\begin{array}{l}\text { Precipitate obtained } \\
\text { as } \mathrm{PbO}_{2} \text { or } \mathrm{PbSO}_{4} \\
\left(\mathrm{~W}_{\mathrm{Pb}}\right),(\mathrm{g})\end{array}$ & $\begin{array}{l}\text { Weight of sample } \\
\text { taken for analysis, } \\
\mathrm{W}_{\text {samp, }} \text { (g) }\end{array}$ & $\begin{array}{l}\text { Concentration of lead found } \\
\text { by electro-gravimetry and } \\
\left.\text { gravimetry (mgkg }{ }^{-1}\right),\left(C\left(M_{P b}\right)_{E x p}\right)\end{array}$ & $\begin{array}{l}\text { Average concentration } \\
\text { of lead found by } \\
\text { electro-gravimetry and } \\
\text { gravimetry, } C_{P b}\left(\mathrm{mg} \mathrm{kg}^{-1}\right)\end{array}$ & $\begin{array}{l}\text { Theoretical Concentration } \\
\text { of stock solution }\left(\mathrm{mg} \mathrm{kg}^{-1}\right) \\
\left(C\left(M_{P b}\right)_{\text {Theo }}\right)\end{array}$ & $\begin{array}{l}\text { Percent of lead analyzed } \\
\text { by electro-gravimetry and } \\
\text { gravimetry }\left(C\left(M_{P b}\right)_{E x p}\right) / C \\
\left.\left(M_{P b}\right)_{T h e o}\right)\end{array}$ & $\begin{array}{l}\text { Average }(\mathrm{g} / 100 \mathrm{~g}) \\
\text { of lead analyzed by } \\
\text { electro-gravimetry } \\
\text { and gravimetry }\end{array}$ \\
\hline$\overline{\mathrm{Pb}-1}$ & $0.0584^{*}$ & $50.5550^{*}$ & $1000.641^{*}$ & 1000.813 & 1001.1253 & $99.952^{*}$ & 99.969 \\
\hline $\mathrm{Pb}-2$ & $0.0585^{*}$ & $50.6247^{*}$ & $1000.974^{*}$ & & & $99.985^{*}$ & \\
\hline $\mathrm{Pb}-3$ & $0.0585^{*}$ & $50.6285^{*}$ & $1000.899^{*}$ & & & $99.977^{*}$ & \\
\hline $\mathrm{Pb}-4$ & $0.0585^{*}$ & $50.6285^{*}$ & $1000.899^{*}$ & & & $99.977^{*}$ & \\
\hline $\mathrm{Pb}-5$ & $0.0582^{*}$ & $50.3812^{*}$ & $1000.654^{*}$ & & & $99.953^{*}$ & \\
\hline $\mathrm{Pb}-6$ & $0.0741^{* *}$ & $50.5765^{* *}$ & $1001.100^{* *}$ & 1000.883 & & $99.988^{* *}$ & 99.976 \\
\hline $\mathrm{Pb}-7$ & $0.0741^{* *}$ & $50.5798^{* *}$ & $1000.896^{* *}$ & & & $99.977^{* *}$ & \\
\hline $\mathrm{Pb}-7$ & $0.0741^{* *}$ & $50.5885^{* *}$ & $1000.936^{* *}$ & & & $99.981^{* *}$ & \\
\hline $\mathrm{Pb}-9$ & $0.0741^{* *}$ & $50.5885^{* *}$ & $1000.764^{* *}$ & & & $99.964^{* *}$ & \\
\hline $\mathrm{Pb}-10$ & $0.0740^{* *}$ & $50.5175^{* *}$ & $1000.818^{* *}$ & & & $99.969^{* *}$ & \\
\hline
\end{tabular}

* Value obtained by electro-gravimetry; ** Value obtained by conventional gravimetry. 
evaluation of uncertainty in chemical and physical analysis [16-19] in various matrixes but the evaluation of the uncertainty by mass is very scanty. The present study highlights the various potential sources of uncertainty involved in the result obtained by conventional gravimetry and electro-gravimetry.

\section{Results and discussion}

The gravimetric analysis only provides analysis of a single element, or a limited group of elements, at a time. In gravimetric analysis, the substance to be analyzed is separated from the other constituents in the form of an insoluble precipitate. The precipitates must be stable, non-hygroscopic and should be unaffected by the atmosphere. Besides this the precipitate should be of known chemical composition, sufficiently insoluble, easy to filter and amounts lost in the washings are insignificant. In most cases gravimetric analysis was used to determine the atomic masses of many elements up to six decimal point accuracy. It provides very less probability for instrumental error and does not require a series of standards for calculation of an unknown and also do not require expensive equipment. Due to its high degree of accuracy when performed correctly it can also be used to calibrate other instruments in lieu of reference standards. There are two basic variations of electro-gravimetric method: controlled-potential or controlled current. Electro-gravimetry analysis is more or less similar to conventional gravimetric analysis. Gravimetric analysis is one of the oldest analytical techniques and very accurate method of analysis when a large sample is available. Modern techniques require much less sample but may not be as accurate. Under the proper conditions, lead may be separated quantitatively from other metals as an insoluble sulfate. In addition, $\mathrm{PbSO}_{4}$ is somewhat soluble in nitric acid so there should be no nitric acid in the solution. So fuming should be strong to ensure complete removal of nitric acid from the solution. The solubility of lead sulfate increases with temperature and is dependant upon the weight percent of sulfuric acid in solution. In controlled-potential electro-gravimetry, a known constant potential is applied to the electrode for a sufficiently time to deposited out $100 \%$ of the analyte. The current decreases as the metal is deposited out. This provides a measure of selectivity if there are two or more metals that can plate out; the metal ion that is more easily reduced can often be plated out quantitatively without any of the other metal also plating out. In controlled-current electrogravimetry, voltage is applied to the working electrode. The current is often on the order of milliamps $(\mathrm{mA})$. If the concentration of metal ion in the electrolysis solution is insufficient to consume all the current, then other reactions such as hydrogen ion reduction may occur in order to consume all the current. And, if any interfering species are present, they will also plate out. In conventional gravimetry the major uncertainties are due to repeatability but in electro-gravimetry several other factors also affect the final results. After analysis of data by both the techniques, purity was found to be $99.97 \pm 0.27$ and $99.98 \pm 0.24 \mathrm{~g} / 100 \mathrm{~g}$, while concentration of lead stock solutions were found to be $1000.81 \pm 2.68$ and $1000.88 \pm 2.44 \mathrm{mg} \mathrm{kg}^{-1}$ using electro-gravimetry and conventional gravimetry technique respectively with $95 \%$ confidence level $(\mathrm{k}=2)$.

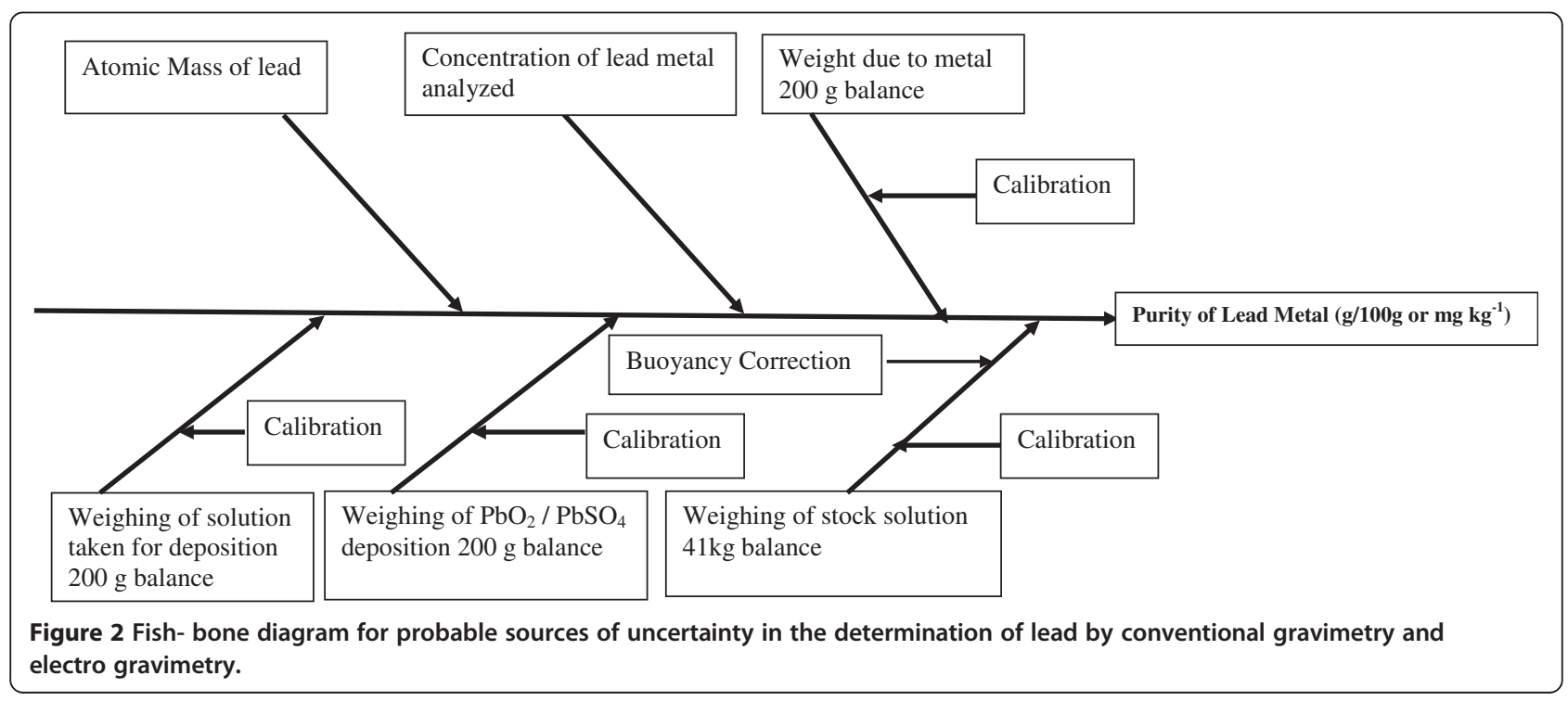




\section{Conclusion}

A generalized scheme for planning a measurement and a simple, practical approach to estimating and combining uncertainties has been demonstrated for the determination of purity of $\mathrm{Pb}$ stick and the concentration of $\mathrm{Pb}$ in stock solution by electro and conventional gravimetric techniques. The results obtained by these two methods are comparable, but standard deviation and combined uncertainty of electro-gravimetry is more in comparisons to conventional gravimetry. So on the basis of results it has been observed that conventional gravimetry is more reliable than electro-gravimetry. But before making any conclusion we should consider the limitation of the process and various sources which contribute uncertainty in final measurement. Gravimetric analysis, if methods are followed carefully, provides for exceedingly precise analysis. The proposed process can be used for the certification of purity of $\mathrm{Pb}$, as traceability statement is primary requirement for the preparation of standard solutions.

\section{Experimental section}

The first set of experiment has been carried out by electrogravimetrically using Toshniwal electrolytic Analyzer system Model E-30, while the other set has been analyzed following classical gravimetry technique. All the weighing work has been carried out using Mettler make; AX 204 model and Sartorius make CC3002 model balances. The glasswares used were of Borosil glass works India Limited. All the acid digestion work was carried out in cleaned laminar flow bench equipped with the proper exhaustive system.

\section{Reagents}

Nitric acid (69\%), Hydrochloric acid (35\%) of GR grade (Guaranteed Reagent) of Merck-India was used after purified by sub boiling point distillation of quartz glass unit. Merck make sulfuric acid (98\%) GR grade was used. The Pb Sticks purity $99.999 \%$ as per certificate procured from Fluka AG, Chem (Germany), Febrik CH-9470 Buchs, 15310, Lot No; 244362587; has been used for solution preparation. De-ionized water (18.2 $\mathrm{M} \Omega$ resistivity) prepared from Millipore milli- Q element water purification system, USA was used throughout the process.

\section{Lead purity determination by conventional gravimetry and electro gravimetry}

Stock solution of $\mathrm{Pb}$ of approximately $1000 \mathrm{mg} \mathrm{kg}^{-1}$ concentration was prepared by dissolving $\mathrm{Pb}$ metal stick in $2 \mathrm{M}$ Sub-boiled nitric acid and final volume was made to $2 \mathrm{~kg}$ by de-ionized water. For conventional gravimetric analysis approximately $50 \mathrm{~g}$ of stock solution was taken in a beaker and it was diluted to $100 \mathrm{~mL}$. To this solution 4-5 ml of concentrated sulfuric acid was added. It was heated on hot plate for strong fuming for at least one hour. Then the beaker was kept in ice cold water bath after addition of $100 \mathrm{ml} \mathrm{de-}$ ionized water in to it and allowed to precipitate $\mathrm{PbSO}_{4}$. The precipitate was filtered through pre-weighted G-4 crucible, washed 3-4 times with $2 \% \mathrm{H}_{2} \mathrm{SO}_{4}$ followed by de-ionized water, then cooled to the room temperature. The precipitate was dried in an oven at $110^{\circ} \mathrm{C}$ for $2 \mathrm{~h}$ there after it was cooled to the room temperature in a desiccator. The weight of the precipitate along with the G4 crucible has been taken followed by drying and cooling to the room temperature several times till a constant weight is achieved. The concentration/purity of lead was calculated by the weight difference.

For electro-gravimetric analysis five replicates of approximate $50 \mathrm{~g}$ stock solution was taken in a beaker and it was diluted to $100 \mathrm{ml}$. To this solution 4-5 drops of concentrated sulfuric acid was added. The anode of the electro analyzer was heated at $120^{\circ} \mathrm{C}$ for $20-30 \mathrm{~min}$. It was cooled in air and weighed. The platinum electrode was connected in the electro analyzer then the current was fixed to 0.05$0.1 \mathrm{~A}$ at $2 \mathrm{~V}$ using a rheostat. The electro analyzer was kept approximate one hour to get stabilized. Further 3 to 5 $\mathrm{ml}$ of de-ionized water was added and anode surface was observed. The darkening of the surface of the electrode indicates the complete deposition of $\mathrm{PbO}_{2}$ onto it. The electrode was taken out from the beaker without stopping current. The electrode was washed thoroughly several times with de-ionized water then it was disconnected from the instrument. The anode was washed again several times with AR grade acetone and dried at $120^{\circ} \mathrm{C}$ for $30 \mathrm{~min}$, cooled in air for $5-10 \mathrm{~min}$ and the final weight was taken. The concentration/purity of $\mathrm{Pb}$ was calculated by the difference in the initial and final weight of the electrode. The flowchart for the purity determination of $\mathrm{Pb}$ by conventional gravimetry and electro gravimetry has been given in Figure 1.

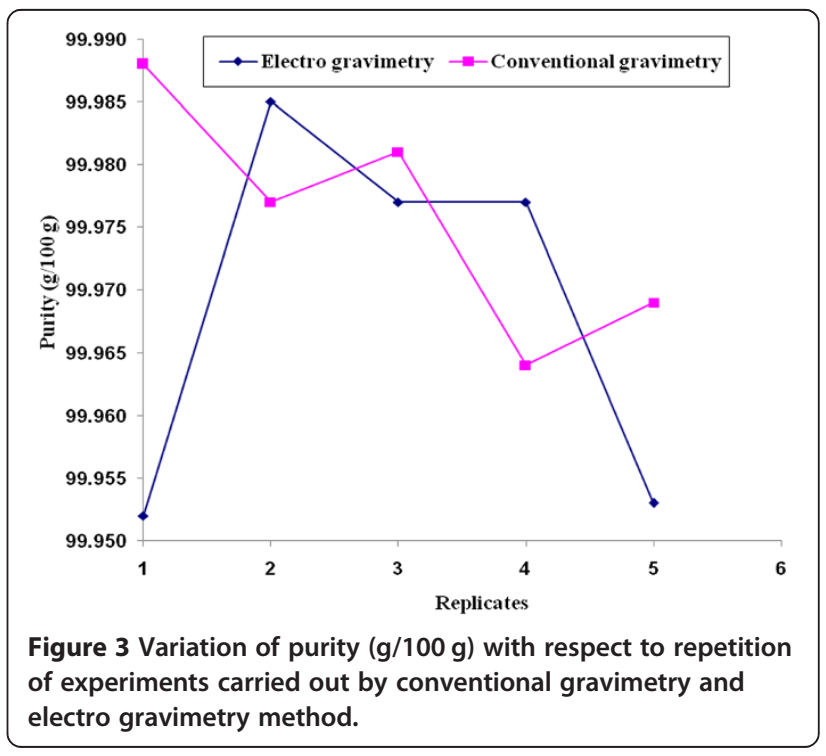




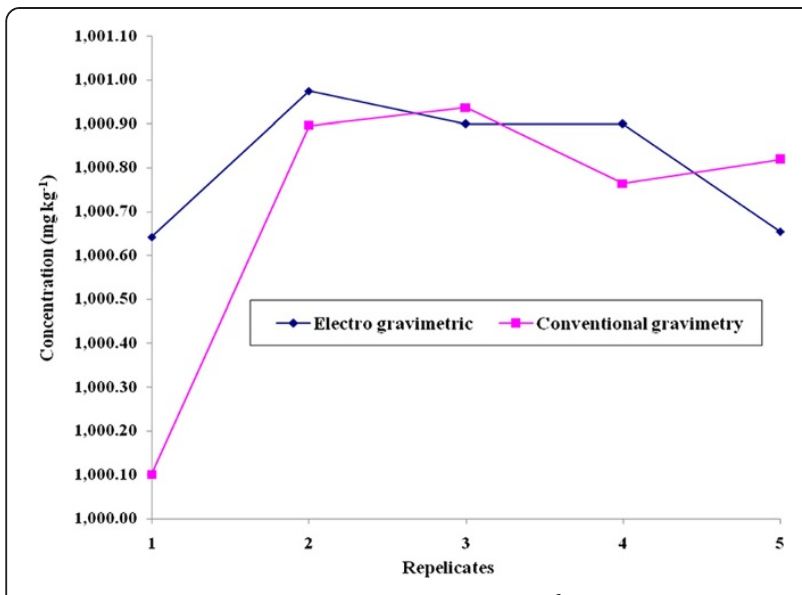

Figure 4 Variation of concentration $\left(\mathrm{mg} \mathrm{kg}^{-1}\right)$ with respect to repetition of experiments carried out by conventional gravimetry and electro gravimetry method.

\section{Calculation of concentration in stock solution and purity} of lead in lead stick

Following the EURACHEM/GUM guidelines concentration of lead $C\left(M_{P b}\right)$ in the stock solution has been evaluated using gravimetry as well electro-gravimetry technique by following equation.

$$
C\left(M_{P b}\right)=\frac{W_{P b} F_{C o n}}{W_{\text {samp }}}
$$

Where; $C\left(M_{P b}\right)=$ Concentration of $\mathrm{Pb}$ in $\mathrm{mg} / \mathrm{kg} ; \mathrm{W}_{P b}=$ Weight of precipitate obtained as $\mathrm{PbO}_{2}$ or $\mathrm{PbSO}_{4}$ by electro Gravimetry and conventional gravimetry respectively (g); $F_{C o n}=$ Conversion factor for $\mathrm{PbO}_{2}(0.86622)$ and $\mathrm{PbSO}_{4}$ $(0.68324)$ in to lead and $W_{\text {samp }}=$ Weight of sample taken for analysis. The purity of $\mathrm{Pb}$ in $\mathrm{g} / 100 \mathrm{~g}$ has been calculated using following equation.

$$
\text { Lead Purity }(\%)=\frac{C\left(M_{P b}\right)_{\text {Exp }}}{C\left(M_{P b}\right)_{\text {Theo }}}
$$

Where; $C\left(M_{P b}\right)_{E x p}=$ Concentration of lead found by experimentally i.e. electro-gravimetry and gravimetry $\left(\mathrm{mg} \mathrm{kg}^{-1}\right) ; C\left(M_{P b}\right)_{\text {Theo }}=$ Concentration of lead found theoretically. The evaluated values for the above factors in equation 1 and 2 are given in Table 1.

There are several sources of uncertainty in chemical metrology like sampling, environmental conditions, uncertainties of masses, volumes, equipment, reference values, measuring equipment approximation, assumptions incorporated in experimental methods, random variations, etc. In this manuscript we have taken major contributions that are stated above in equation-1. In accordance with GUM, the combined uncertainty for the mathematical model, which is a product or quotient form, is given by:

$$
\left[u_{c}(y) / y\right]^{2}=\sum_{i=1}^{N}\left[p_{i} u\left(x_{i}\right) / x_{i}\right]^{2}
$$

The combined standard uncertainty $\mathrm{u}_{\mathrm{c}}(\mathrm{y})$ is an estimated standard deviation and characterizes the dispersion of the values that could reasonably be attributed to the measurand ' $y$ '. The sensitivity coefficient $=p_{i} y /$ $\mathrm{x}_{i}$, Where $\mathrm{p}_{\mathrm{i}}$ is the power of the terms in the equation (1).

\section{Evaluation of associated uncertainty budget}

The evaluation of the uncertainty of every step of the experiment is one of the requirements of the standard ISO/IEC17025 for certain test methods to get accreditation. Gravimetry analysis of $\mathrm{Pb}$ evaluation of combined uncertainty in such measurand is very complicated as there are various parameters to contribute uncertainty in the entire process. In the evaluation of $\mathrm{Pb}$ uncertainty in liquid solution there are several major sources which directly influence the final results. Out of which weighing has major contribution for adding uncertainty in the measure-

\begin{tabular}{|c|c|c|c|c|c|}
\hline Sources & $\mathrm{x}$ & $\mathrm{u}_{\text {std }}(\mathrm{x})$ & $\mathrm{u}_{s t d}(\mathrm{x}) / \mathrm{X}$ & Uc (\%) & $U_{E x}\left(\mathrm{mg} \mathrm{kg}^{-1}\right) ; \mathrm{k}=2$ \\
\hline Precision & $99.976 \%$ & $0.0048 \%$ & 0.0000476 & 0.122 & 0.244 \\
\hline Atomic mass of $\mathrm{PbSO}_{4}$ & $303.253 \mathrm{~g}$ & $0.0578 \mathrm{~g}$ & 0.000191 & & \\
\hline Balance (Mettler $220 \mathrm{~g}$ ) & $2.015 \mathrm{~g}$ & $0.00005 \mathrm{~g}$ & 0.000025 & & \\
\hline Balance (Sartorius 41 kg) & $2012.734 \mathrm{~g}$ & $0.1345 \mathrm{~g}$ & 0.000067 & & \\
\hline Error in buoyancy & $2014.745 \mathrm{~g}$ & $2.0012 \mathrm{~g}$ & 0.000993 & & \\
\hline Weight of $\mathrm{PbSO}_{4}$ precipitate (Mettler $220 \mathrm{~g}$ ) & $0.0741 \mathrm{~g}$ & $0.00005 \mathrm{~g}$ & 0.000675 & & \\
\hline Weight of solution for deposition(Mettler $220 \mathrm{~g}$ ) & $50.5918 \mathrm{~g}$ & $0.00005 \mathrm{~g}$ & 9.883E-07 & & \\
\hline
\end{tabular}
ment of $\mathrm{Pb}$ due to the air buoyancy. The combined

Table 2 Summary table for Uncertainty Budget for purity determination in $(\mathrm{g} / 100 \mathrm{~g})$ by classical gravimetry 


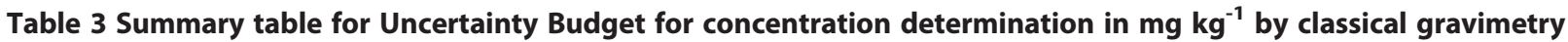

\begin{tabular}{|c|c|c|c|c|c|}
\hline Sources & $x$ & $\mathrm{u}_{\text {std }}(\mathrm{x})$ & $\mathrm{u}_{s t d}(\mathrm{x}) / \mathrm{X}$ & $\mathrm{Uc}\left(\mathrm{mg} \mathrm{kg}^{-1}\right)$ & $\mathrm{U}_{E x}\left(\mathrm{mg} \mathrm{kg}{ }^{-1}\right) ; \mathrm{k}=2$ \\
\hline Precision & $1000.883 \mathrm{mg} / \mathrm{kg}$ & $0.047 \mathrm{mg} / \mathrm{kg}$ & 0.000047 & 1.22 & 2.44 \\
\hline Atomic mass of $\mathrm{PbSO}_{4}$ & $303.253 \mathrm{~g}$ & $0.0578 \mathrm{~g}$ & 0.000191 & & \\
\hline Balance (Mettler $220 \mathrm{~g}$ ) & $2.015 \mathrm{~g}$ & $0.00005 \mathrm{~g}$ & 0.000025 & & \\
\hline Balance (Saritorious 41 kg) & $2012.734 \mathrm{~g}$ & $0.1345 \mathrm{~g}$ & 0.000067 & & \\
\hline Error in buoyancy & $2014.745 \mathrm{~g}$ & $2.0012 \mathrm{~g}$ & 0.000993 & & \\
\hline Weight of $\mathrm{PbSO}_{4}$ precipitate (Mettler $220 \mathrm{~g}$ ) & $0.0741 \mathrm{~g}$ & $0.00005 \mathrm{~g}$ & 0.000675 & & \\
\hline Balance (Sartorios $41 \mathrm{~kg}$ ) for stock solution & $50.5918 \mathrm{~g}$ & $0.00005 \mathrm{~g}$ & 9.883E-07 & & \\
\hline
\end{tabular}

uncertainty for concentration of stock solution of lead is given by:

$$
u_{c}\left(C_{M_{P b}}\right)=C_{M_{P b}} \sqrt{\left[\frac{u(p)}{p}\right]^{2}+\left[\frac{u\left(. P b_{A t . W t}\right)}{P b_{\text {At.wt. }}}\right]^{2}+\left[\frac{u(B)}{W_{\text {Metal }}}\right]^{2}+\left[\frac{u(B)}{W_{\text {Obs. Stock soln. }}}\right]^{2}+\left[\frac{u(B u)}{W_{\text {True mass stock soln }}}\right]^{2}+\left[\frac{u(B)}{W_{\text {ppt }}}\right]^{2}+\left[\frac{u(B)}{W_{\text {Aliquote }}}\right]^{2}}
$$

Similarly, the combined uncertainty for purity of lead metal is given by:

$$
u_{c}\left(p_{P b}\right)=p_{P b} \sqrt{\left[\frac{u_{c}\left(C_{M_{P b}}\right)}{C_{M_{P b}}}\right]^{2}+\left[\frac{u\left(P b_{A t . W t}\right)}{P b_{\text {At.wt. }}}\right]^{2}+\left[\frac{u(B)}{W_{\text {Metal }}}\right]^{2}+\left[\frac{u(B)}{W_{\text {Obs Stock soln. }}}\right]^{2}+\left[\frac{u(B u)}{W_{\text {True mass stock soln }}}\right]^{2}+\left[\frac{u(B)}{W_{p p t}}\right]^{2}+\left[\frac{u(B)}{W_{\text {Aliquote }}}\right]^{2}}
$$

Where, $\mathrm{uC}$ is the combined uncertainty of the concentration of stock solution; $C\left(M_{P b}\right)$ is the concentration of lead in $\mathrm{mg} \mathrm{kg}^{-1} ; \mathrm{u}(\mathrm{p}) / \mathrm{p}$ is the relative uncertainty of purity of lead metal; up is the combined uncertainty of the purity of lead; $p_{P b}$ is the purity of lead; $\mathrm{u}(\mathrm{Cmpb}) / \mathrm{Cmpb}$ is the relative uncertainty of concentration of stock solution; $\mathrm{u}(\mathrm{Pb}$ at. $\mathrm{Wt}) / \mathrm{Pb}$ at; $\mathrm{Wt}$ is the relative uncertainty of atomic mass of lead ; $u(B) / W_{\text {metal }}$ is the relative uncertainty due to weighing of lead stick; $\mathrm{u}(\mathrm{B}) / \mathrm{W}_{\text {stock }}$ solution is the relative uncertainty due to weighing of stock solution; $\mathrm{u}(\mathrm{Bu}) / \mathrm{W}_{\text {true }}$ mass is the relative uncertainty due to buoyancy correction; $\mathrm{u}(\mathrm{B}) / \mathrm{Wppte}$. is the relative uncertainty due to weighing of precipitate; $\mathrm{u}(\mathrm{B}) / \mathrm{W}_{\text {aliquot }}$ is the relative uncertainty due to weighing of aliquot. The individual uncertainty is evaluated either by 'Type A' (i.e. using statistical analysis of a series of observations) or by 'Type B' (i.e. using other means than the statistical analysis of a series of observations). The components and sub components which contribute towards the uncertainty are shown in Fish- bone diagram (Figure 2). The uncertainty evaluation in every step of the experiment has been discussed in the following sub-sections:

\section{Uncertainty in purity of lead metal}

To get the uncertainty value associated with the purity of the $\mathrm{Pb}$ metal, the uncertainty due to concentration

\begin{tabular}{|c|c|c|c|c|c|}
\hline Sources & $\mathrm{x}$ & $\mathrm{u}_{\text {std }}(\mathrm{x})$ & $\mathrm{u}_{s t d}(\mathrm{x}) / \mathrm{X}$ & Uc (\%) & $\mathrm{U}_{E x}(\%) ; \mathrm{k}=\mathbf{2}$ \\
\hline Precision (P) & $99.969 \%$ & $0.0069 \%$ & 0.00007 & 0.134 & 0.268 \\
\hline Atomic mass of $\mathrm{PbO}_{2}$ (At. Wt) & $239.199 \mathrm{~g}$ & $0.0577 \mathrm{~g}$ & 0.000241 & & \\
\hline Balance (Mettler $220 \mathrm{~g})$; $\left(\mathrm{W}_{\text {metal }}\right)$ & $2.015 \mathrm{~g}$ & $0.00005 \mathrm{~g}$ & 0.000025 & & \\
\hline Balance (Sartorious 41 kg) (Wobs. stock solution $)$ & $2012.734 \mathrm{~g}$ & $0.1345 \mathrm{~g}$ & 0.000067 & & \\
\hline Error buoyancy; (Bu w.r.t W $\mathrm{true}_{\text {true mass stock soln. }}$ ) & $2014.745 \mathrm{~g}$ & $2.0012 \mathrm{~g}$ & 0.000993 & & \\
\hline weight of $\mathrm{PbO}_{2}$ (Mettler $\left.220 \mathrm{~g}\right)\left(\mathrm{W}_{\text {ppt }}\right)$ & $0.0584 \mathrm{~g}$ & $0.00005 \mathrm{~g}$ & 0.000856 & & \\
\hline Weight of soln. for deposition(Mettler $220 \mathrm{~g}$ ) ( $\left.W_{\text {aliquote }}\right)$ & $50.5618 \mathrm{~g}$ & $0.00005 \mathrm{~g}$ & 0.000001 & & \\
\hline
\end{tabular}

Table 4 Summary table for Uncertainty Budget for purity determination in $(g / 100 g)$ by electro-gravimetry 
Table 5 Summary table for Uncertainty Budget for concentration determination in $\mathrm{mg} \mathrm{kg}^{-1}$ by electro-gravimetry

\begin{tabular}{|c|c|c|c|c|c|}
\hline Sources & $\mathrm{x}$ & $u_{\text {std }}(x)$ & $u_{\text {std }}(x) / X$ & Uc (mg/kg) & $\mathrm{U}_{\mathrm{Ex}}\left(\mathrm{mg} \mathrm{kg}{ }^{-1}\right) ; \mathrm{k}=2$ \\
\hline Precision $\left(\mathrm{C}_{\mathrm{MPb}}\right)$ & $1000.813 \mathrm{mg} / \mathrm{kg}$ & $0.069 \mathrm{mg} / \mathrm{kg}$ & 0.000069 & 1.338 & 2.676 \\
\hline Atomic mass of $\mathrm{PbO}_{2}$ & $239.199 \mathrm{~g}$ & $0.0577 \mathrm{~g}$ & 0.000241 & & \\
\hline Balance (Mettler $220 \mathrm{~g}$ ) & $2.015 \mathrm{~g}$ & $0.00005 \mathrm{~g}$ & 0.000025 & & \\
\hline Balance (Sartorious 41 kg) & $2012.734 \mathrm{~g}$ & $0.1345 \mathrm{~g}$ & 0.000067 & & \\
\hline Error in buoyancy & $2014.745 \mathrm{~g}$ & $2.0012 \mathrm{~g}$ & 0.000993 & & \\
\hline weight of $\mathrm{PbO}_{2}$ (Mettler $220 \mathrm{~g}$ ) & $0.0584 \mathrm{~g}$ & $0.00005 \mathrm{~g}$ & 0.000856 & & \\
\hline $\begin{array}{l}\text { Weight of solution taken for electro-gravimetry } \\
\text { experiment (Mettler } 220 \mathrm{~g} \text { ) }\end{array}$ & $50.5618 \mathrm{~g}$ & $0.00005 \mathrm{~g}$ & 0.000001 & & \\
\hline
\end{tabular}

obtained using equation-1 has to be considered. It could be quantified by the precipitate obtained by the repetition of experiments carried out for both the methods. The standard deviation of the measurements can be considered for the standard uncertainty with the degrees of freedom. Figures 3 and 4 shows the variation of the purity value $(\mathrm{g} / 100 \mathrm{~g})$ and concentration $\left(\mathrm{mg} \mathrm{kg} \mathrm{kg}^{-1}\right)$ obtained from the five replicates. Similarly the uncertainty value associated with the concentration is given in Tables 2, 3, 4 and 5.

\section{Uncertainty in atomic mass}

Atomic mass of the element with uncertainty is obtained from the IUPAC Technical report [20]. As lead obtained as $\mathrm{PbO}_{2}$ and $\mathrm{PbSO}_{4}$ by weight, hence the atomic mass of $\mathrm{O} \& \mathrm{~S}$ are also taken into consideration in the uncertainty calculation. To obtain the standard uncertainty due to atomic mass the IUPAC quoted uncertainty considers a rectangular distribution as given in the Table 6.

\section{Uncertainty in weighing}

There are several factors such as repeatability, nonlinearity, sensitivity, air buoyancy, which influence to the weight of the material while weighing in an electronic balance. There are two types of balances have been used for the whole experiment as given in the section 2 of this paper. The initial weight of approximately $2 \mathrm{~g} \mathrm{~Pb}$ stick was taken in a micro balance and the stock metal solution weight taken in a balance of $41 \mathrm{~kg}$. The amount of stock solution taken for deposition of $\mathrm{Pb}$ and the weight of the precipitate obtained after conventional gravimetry method as well as electrolytic deposition on electrode are also taken in micro balance. The uncertainty associated due to calibration of the balance is taken from the calibration certificate provided by CSIR-National Physical Laboratory, New Delhi, National metrology institute of India and are given in Table 7. But in the case of the preparation of $2 \mathrm{~kg}$ weight solution, the correction due to air buoyancy has been included as the weight taken in presence of air influences much in the observed weight. The reference regarding calculation of buoyancy correction is very scanty. The EURACHEM/ CITAC Guide CG 4 is also not elaborating the uncertainty in weighing properly. In this paper effort has been taken to calculate the true weight considering the buoyancy correction.

\section{Calculation of buoyancy correction}

In the proposed process uncertainty due to buoyancy has been consider first time, which has major effects on weighing. The mass of the solution taken in an electronic balance is actually measure its weight force. So in presence of air the weight taken in an electronic balance varies remarkably for the same sample. As there is a deviation in the weight taken in an electronic balance due to air buoyancy, so the total uncertainty budget by mass is calculated considering buoyancy correction. The EURACHEM/CITAC Guide CG 4 [21]; Jones, Schoonover and Gonz'alez [22-24] have presented the process to calculate correction due to air buoyancy. For the calibration of single-pan electronic control balance, a standard weight of known mass has to be used to builds an apparent mass calibration into the balance. The

Table 6 Uncertainty in atomic mass of lead Metal

\begin{tabular}{lcclcr}
\hline Element & Atomic mass of lead $(\mathbf{g})$ & Uncertainty in weight $\mathbf{( g )}$ & Distribution & Standard uncertainty & Combined standard uncertainty \\
\hline $\mathrm{Pb}$ & 207.19 & 0.1 & Rectangular & $0.1 / \sqrt{ } 3=0.05773$ & $0.0578\left(\mathrm{PbSO}_{4}\right)$ \\
$\mathrm{S}$ & 32.065 & 0.005 & Rectangular & $0.005 / \sqrt{ } 3=0.00289^{\#}$ & \\
$\mathrm{O}^{\#}$ & 15.9994 & 0.0003 & Rectangular & $0.0003 / \sqrt{ } 3=0.00017^{\#}=$ \\
& & & & $0.00017^{*} 4=0.00068$ & \\
$\mathrm{O}^{\#}$ & 15.9994 & 0.0003 & Rectangular & $0.0003 / \sqrt{ } 3=0.00017^{\#}=$ & $0.0577(\mathrm{PbO})$ \\
& & & & $0.00017^{*} 2=0.00034$ & \\
\hline
\end{tabular}


Table 7 Uncertainty due to balance of Ohaus make (200 g) and Sartorius make (41 kg)

\begin{tabular}{|c|c|c|c|c|c|}
\hline Weight component & $\begin{array}{c}\text { Balance used for } \\
\text { weighing }\end{array}$ & $\begin{array}{l}\text { Weight } \\
\text { taken }(g)\end{array}$ & $\begin{array}{c}\text { Uncertainty in weight as per } \\
\text { certificate at } k=2\end{array}$ & Distribution & $\begin{array}{l}\text { Standard uncertainty in total } \\
\text { weight } u(x) / x\end{array}$ \\
\hline Weight of the metal $\mathrm{m}(\mathrm{g})$ & $\begin{array}{c}\text { Mettler AX } 204 \\
220 \mathrm{~g}\end{array}$ & 2.015 & 0.0001 & Normal & $0.0001 / 2=0.00005$ \\
\hline $\begin{array}{l}\text { Weight of solution taken for } \\
\mathrm{PbO}_{2} \text { deposition }\end{array}$ & do & 50.5618 & 0.0001 & Normal & $0.0001 / 2=0.00005$ \\
\hline Weight of $\mathrm{PbO}_{2}$ deposited & do & 0.0584 & 0.0001 & Normal & $0.0001 / 2=0.00005$ \\
\hline $\begin{array}{l}\text { Weight of solution taken for } \\
\mathrm{PbSO}_{4} \text { deposition }\end{array}$ & do & 50.5918 & 0.0001 & Normal & $0.0001 / 2=0.00005$ \\
\hline Weight of $\mathrm{PbSO}_{4}$ deposited & do & 0.0741 & 0.0001 & Normal & $0.0001 / 2=0.00005$ \\
\hline Weight of stock solution & $\begin{array}{c}\text { Sartorius; CC3002; } \\
41 \mathrm{~kg}\end{array}$ & 2012.734 & 0.269 & Normal & $0.269 / 2=0.1345$ \\
\hline
\end{tabular}

reference density of the apparent mass scale is the density of the standard mass used for the calibration and the reference air density is the air density at the time of calibration.

Air density can be calculated using the following equation.

$$
\rho_{\mathrm{a}}=\frac{0.34848 \times P-0.009 \times R H \times \exp (0.062 \times T)}{(273.154+T)}
$$

Putting the following values of temperature, pressure and humidity in the above equation. The weight of an unknown sample weighed on the balance is then

$$
W_{T}=\frac{W_{O b s}}{\left(1-\rho_{a} M / \rho_{s}\right)} \times\left(1-\rho_{a} / \rho_{X}\right)
$$

Where; $\mathrm{W}_{o b s}$ is the observed weight of the unknown sample; $\mathrm{W}_{T}$ is the True weight of the unknown sample; $\rho_{a}$ is the density of air at the time of balance calibration;

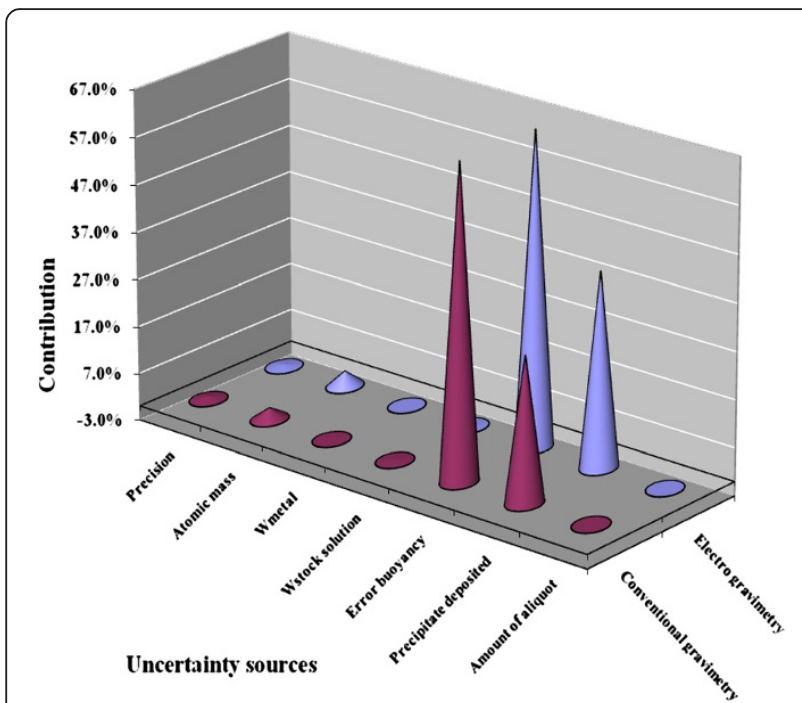

Figure 5 Percentage contribution of uncertainty source included in the lead determination by conventional gravimetry and electro gravimetry. $\rho_{a} M$ is the density of air at the time of measurement; $\rho_{x}$ is the density of the standard used to calibrate the balance; $\rho_{s}$ is the density of the sample. It is shown that the relative error in neglecting buoyancy is about $0.1 \%$. So, the exact value of the error is easily calculated as follows

$$
\mathrm{W}_{o b s}=\mathrm{W}_{T} \times \mathrm{F} \text {; where, } F=\frac{\left(1-\rho_{a} M / \rho_{S}\right)}{\left(1-\rho_{a} / \rho_{x}\right)}
$$

In this case $\rho_{\mathrm{s}}$ is the density of the elemental solution which is nothing but $2 \%$ acidified de-ionized water. Putting the value of ' $\mathrm{F}$ ' and $\mathrm{W}_{o b s}$ in equation -5 , so true weight can be calculated. The true weight of the stock solution is found to be $2014.745 \mathrm{~g}$. The relative percent error in neglecting buoyancy is given by

$$
\left(\mathrm{W}_{T}-\mathrm{W}_{\text {obs }}\right) 100 / \mathrm{W}_{T}=100(1-\mathrm{F})
$$

The absolute error $\left(\mathrm{Abs}_{e r}\right)$ is given by

$\mathrm{Abs}_{e r}=\mathrm{W}_{T}(1-\mathrm{F})$

Putting the value of $\mathrm{W}_{\mathrm{T}}$ \& $\mathrm{F}$ in Eq. (6)

Absolute error due to Buoyancy is calculated as $2.0012 \mathrm{~g}$

So the relative error is $\mathrm{u}\left(\mathrm{Abs}_{e r}\right) / \mathrm{W}_{T}=0.000993$.

The uncertainties associated with each component are combined and expanded Uncertainty with 95\% confidence level.

\section{Calculation of combined uncertainty}

The concentration of lead $\left(\mathrm{mg} \mathrm{kg}^{-1}\right)$ and purity (g/100g) in five replicates following electro-gravimetry and conventional gravimetry has been determined using equation-1 and 2 respectively which is described in section 5.1 Substituting the values from Table 1 into eqution-1 and 2, the concentration and purity of lead respectively has been calculated for each experiment. The combined uncertainties in the determination of both concentration and purity of lead for electro-gravimetry and conventional gravimetry have been calculated by putting the value in eqution-3 and 4 . The expanded uncertainty was calculated at $95 \%$ confidence level at $\mathrm{k}=2$. The percentage contribution of each uncertainty source considered in the total uncertainty budget is plotted for 
both gravimetric methods (Figure 5). It shows that the maximum contribution of uncertainty lies due to the weighing of precipitate of $\mathrm{PbO}_{2}, \mathrm{PbSO}_{4}$ and the stock lead solution. However, the associated uncertainty value obtained for the electro gravimetric method is more as compared to the conventional gravimetric method due to the uncertainty due to atomic mass and the precipitated deposited sources.

\section{Competing interests}

The authors declare that they have no competing interests.

\section{Authors' contributions}

Nahar made a significant contribution to acquisition of data, analysis and manuscript preparation. Experiential work has been carried out by Nahar and Niranjan. SST has done theoretical calculation of buoyancy correction. KS and DS and PKG made a significant contribution experimental design and data analysis. All the authors read and approved the final manuscript

\section{Acknowledgement}

The authors are grateful to Prof. R. C. Budhani; Director, National Physical Laboratory for encouragement and permission to publish this work.

Received: 6 February 2013 Accepted: 10 June 2013

Published: 26 June 2013

\section{References}

1. CODEX alimentarius commission on food and agriculture organization of the United Nations: FAO/WHO Food standards programme $31^{\text {st }}$ Session. Geneva, Switzerland; 2008.

2. Rubio C, González-Iglesias T, Revert C, Reguera II, Gutiérrez AJ, Hardisson A Lead dietary intake in Spanish population (canary islands). J. Agric. Food Chem 2005, 53(16):6543-6549.

3. Lead (Pb) by isotope dilution ICPMS for CA Prop. 65 in antacids, supplements, and raw materials: WCAS (West Coast Analytical Service) A chemical testing laboratory for trace chemical analysis using ICP-MS, GCMS, LC-MS/MS, FTIR, GC, HPLC, IC, ICP-OES, XRF, NMR, and UV-Vis for the pharmaceutical, food supplement, and environmental industries. Available at http://www.wcaslab. com/index.htm.Jan 2002.

4. United States Department of Agriculture Food Safety and Inspection Service, Office of Public Health Science: Determination of Cadmium and Lead by ICP-MS. ; 2006:1-14. http://www.fsis.usda.gov/shared/PDF/CLG_TM_3_01.pdf.

5. Sheppard BS, Heitkemper DT, Gaston CM: Microwave digestion for the determination of arsenic, cadmium, and lead in seafood products by inductively coupled plasma. Atomic Emission and Mass Spectrometry, Analyst 1994, 119:1683-1686.

6. Ndung'u K, Hibdon S, Flegal AR: Determination of lead in vinegar by ICPMS and GFAAS: evaluation of different sample preparation procedures. Talanta 2004, 64(1):258-263.

7. Hahn E, Hahn K, Mohl C, Stoeppler M, Zeeman SS-GFAAS: An ideal method for the evaluation of lead and cadmium profiles in Birds' feathers. Fresenius' J. Anal. Chem 1990, 337:306-309.

8. Zhang X, Li B, Gao W, Zhang YX: GFAAS determination of trace lead in toothpase using L'vov platform. Guang Pu Xue Yu Guang Pu Fen Xi 1999, 19(3):388-391.

9. Bashir W, Butler SG, Paull B: Determination of lead in water samples using Ion chromatography with a xylenol orange containing eluent. Analytical Letters 2001, 34(9):1529-1540.

10. Sellers NG: lon-exchange separation and determination of lead in steel by atomic absorption anal. Chem 1972, 44(2):410-411.

11. Vogel Al: A text-book of quantitative inorganic analysis. 3rd edition. London: Longmans Green; 1961:501-502.

12. Joseph LM: Gravimetric determination of lead in solution of lead as subacetate. Journal of Pharmaceutical Sciences 1931, 4(20):363-364. doi:10.1002/jps.3080200412, 006.

13. Van Der Veen AMH, Delft VSL: Revision of the guide to the expression of uncertainty in measurement, eurachem WS 6-7 June 2011, the Netherlands eurachem workshop "recent developments in measurement uncertainty". Lisbon, Portugal; 2011.
14. International vocabulary of metrology - basic and general concepts and associated terms (VIM $3^{\text {rd }}$ edition), JCGM 200. ; 2012

15. ISO/DTS 21748: Guide to the Use of repeatability, reproducibility and trueness estimate in measurement uncertainty estimation. Geneva, Switzerland: ISO; 2003.

16. Kayal N, Singh N, Ojha VN, Gupta PK: Evaluation and expression of uncertainty in the determination of alumina in deodorants using complexometric method. Journal of Testing and Eval 2009, 37:321-328.

17. Synek $V$, Subrt $P$, Marececk J: Uncertainty of mercury determination in biological materials using an atomic absorption spectrometer-AMA 254. Accred Qual Assur 2000, 5:58-65.

18. Singh N, Ojha VN, Kayal N, Ahuja T, Gupta PK: Quantifying uncertainty in the measurement of arsenic in suspended particulate matter by atomic absorption spectrometry with hydride generator. Chemistry Central Journal 2011, 5:17.

19. Kayal N, Singh N: The quantitative estimation of silica in rice husk Ash by titrimetric. MAPAN-Journal of Metrology Society of India 2010, 25(2):115-123.

20. De Laeter JR, Bohlke JK, Bievre PD, Hidaka H, Peiser HS, Rosman KJR, Taylor PDP: Atomic weights of the elements: review 2000. Pure \& Applied Chemistry 2003, 75(6):683-800.

21. Elison SLR, Rosslein M, Williams A: Quantifying uncertainty in analytical measurement. EURACHEM / CITAC 2000, 1.

22. Jones FE: The air density equation and the transfer of the mass unit. Res. Nat. Bur. Stand 1978, 83(5):419-428.

23. Randall M, Schoonover RM, Jones FE: Air buoyancy correction in high accuracy weighing on analytical balances. Anal. Chem 1981, 53:900-902.

24. Gonz'alez AG, Herrador MA: The assessment of electronic balances for accuracy of mass measurements in the analytical laboratory. Accred Qual Assur 2007, 12:21-29.

doi:10.1186/1752-153X-7-108

Cite this article as: Singh et al: Evaluation of purity with its uncertainty value in high purity lead stick by conventional and electro-gravimetric methods. Chemistry Central Journal 2013 7:108.

Publish with ChemistryCentral and every
scientist can read your work free of charge
"Open access provides opportunities to our
colleagues in other parts of the globe, by allowing
anyone to view the content free of charge."
W. Jeffery Hurst, The Hershey Company.
- available free of charge to the entire scientific community
- peer reviewed and published immediately upon acceptance
- cited in PubMed and archived on PubMed Central
- yours - you keep the copyright
submit your manuscript here:
http://www.chemistrycentral.com/manuscript/

